\title{
CONCEPÇÕES SOBRE CURRÍCULO NA EDUCAÇÃO INFANTIL: ressonâncias da pedagogia da infância em narrativas de
professoras pedagogia da infância em narrativas de
professoras
}

Marcelo Oliveira da Silva

Universidade Federal do Rio Grande do Sul - UFRGS

Rodrigo Saballa de Carvalho

Universidade Federal do Rio Grande do Sul - UFRGS

\section{Resumo}

Este artigo, a partir do campo dos Estudos Sociais da Infância e das contribuições dos Estudos sobre Currículo, tem como objetivo central discutir as concepções de professoras sobre o currículo na Educação Infantil. O artigo é decorrente de uma pesquisa de pós-doutoramento que busca mapear, nas narrativas de professoras, os modos como a Pedagogia da Infância têm incidido na prática docente. Metodologicamente, visando à geração dos dados da pesquisa, foram realizadas entrevistas com 20 professoras de Educação Infantil da rede pública e privada de ensino. Com base na análise do conteúdo das narrativas, observou-se a recorrência de três concepções que configuram os modos como as professoras entendem o currículo da Educação Infantil. Nesse sentido, são recorrentes, nas narrativas analisadas, (1) o currículo emergente, (2) a figura da criança protagonista e (3) a Pedagogia da Escuta como elementos constituintes do currículo da Educação Infantil que deve ser efetivado por meio de uma Pedagogia de Projetos. Com a análise dos dados, é possível inferir que a Pedagogia da Infância, marcadamente constituída por teorizações da Educação Infantil italiana, tem tido visível impacto na formação da professora de Educação Infantil, com fundamento em uma gramática de formação docente presente em discursos e práticas.

Palavras-chave: Educação Infantil; Currículo; Infância; Docência; Pedagogia da Infância.

\begin{abstract}
This article, based on the field of Social Studies of Childhood and on the contributions of Curriculum Studies, has the central goal of discussing the conceptions of teachers about the curriculum in Early Childhood Education. The article is the result of a post-doctoral research that seeks to map, in the narratives of teachers, the ways in which Early Childhood Pedagogy has affected teaching practices. Methodologically, in order to generate the research data, interviews were conducted with 20 teachers of Early Childhood Education from public and private schools. Based on the analysis of the content of the narratives, there was a recurrence of three conceptions that configure the ways in which teachers understand the curriculum of Early Childhood Education. In the analyzed narratives, (1) the emergent curriculum, (2) the figure of the child as protagonist, and (3) the Pedagogy of Listening are recurrent as constituent elements of the Early Childhood curriculum that must be carried out through Project-based Learning. With the analysis of the data, it is possible to infer that Early Childhood Pedagogy, markedly constituted by theories of Italian Early Childhood Education, has had a visible impact on the training of Early Childhood Education teachers, based on a grammar of teacher education present in discourses and practices.
\end{abstract}

Keywords: Early Childhood Education; Curriculum; Childhood; Teaching; Early Childhood Pedagogy. 


\section{Considerações iniciais}

[...] hoje assistimos a uma quase esquizofrenia educativa em que se naturalizou a distância entre as propostas e a realidade pedagógica, experienciada por adultos e crianças (Oliveira-Formosinho, 2007, p. 13).

Este artigo é decorrente de uma pesquisa de pós-doutorado ${ }^{1}$ situada no campo dos Estudos Sociais da Infância e nas contribuições dos Estudos sobre Currículo. Seu objetivo foi investigar como os princípios presentes nas práticas docentes de professoras de Educação Infantil (creche e pré-escola) têm se aproximado das discussões teóricas sobre infância, currículo, didática e docência sendo desenvolvidas na última década no campo epistêmico da Pedagogia da Infância. A justificativa de tal investigação foi pautada em nosso entendimento de que a Pedagogia é "um espaço ambíguo, já não de um-entre-dois, a teoria e a prática, mas antes de um-entre-três, as ações, as teorias e as crenças, em uma triangulação interativa e constantemente renovada" (Oliveira-Formosinho, 2007, p. 14, grifos nossos) pelas professoras atuantes nas escolas.

A partir desse ponto de vista, focalizamos a Pedagogia da Infância (Rocha, 2001; Barbosa, 2010) em nossa pesquisa pelo fato de ela "ser um campo de investigação e de ação pedagógica na Educação Infantil” (Carvalho, 2019, p. 86) que incidiu na definição de políticas curriculares, como as Diretrizes Curriculares Nacionais de Educação Infantil (DCNEI) (MEC, 2009) e a Base Nacional Comum Curricular (BNCC) (Brasil, 2017), para a docência na primeira etapa da Educação Básica. Além disso, entendemos que os princípios da Pedagogia da Infância têm reverberado na formação inicial e continuada de professores que atuam com crianças de 0 a 5 anos e 11 meses idade, assim como nas pesquisas realizadas no âmbito da Educação Infantil.

Esclarecemos que a Pedagogia da Infância tem como "objeto de preocupação a própria criança e seus processos de constituição como seres humanos em diferentes contextos sociais, sua cultura, suas capacidades intelectuais, criativas, estéticas, expressivas e emocionais" (Rocha, 2001, p. 31). Para tanto, no contexto da Pedagogia da Infância, defende-se:

a) a compreensão da criança como sujeito de direitos (Barbosa, 2010);

b) "a definição de indicativos pedagógicos que possibilitem às crianças a experiência da infância, de forma a tomar parte em projetos educacionais fundados na democracia, na diversidade e participação social" (Barbosa, 2010, p. 1);

c) o desenvolvimento de uma ação pedagógica docente "comprometida política e socialmente, que dê suporte às aprendizagens das crianças, por meio de um contexto educativo que leve em consideração tempos, espaços, materiais e as relações entre os sujeitos" (Carvalho, 2019, p. 87);

d) a defesa de que não sejam reproduzidas práticas do Ensino Fundamental na Educação Infantil;

e) o entendimento de que termos como "aula, aluno, ensino, escola e conteúdo, devem ser ressignificados pelo fato de estarem pautados em uma concepção escolarizante da infância" (Carvalho, 2015, p. 467);

f) o apoio a uma concepção plural de currículo na "qual toda e qualquer ação educativa, deve considerar as crianças e os contextos socioculturais que definem sua infância" (Barbosa, 2010, p. 1).

Alinhadas aos princípios elencados, as DCNEI (MEC, 2009), a partir do argumento de que a criança é um sujeito histórico, geográfico, produtor de cultura e detentor de direitos, definem as interações e as brincadeiras como eixos fundamentais do currículo. Precisamente nesse sentido, as DCNEI (MEC, 2009) estabelecem, em seu artigo $3^{\circ}$, que o currículo da Educação Infantil:

[...] é concebido como um conjunto de práticas que buscam articular as experiências e os saberes das crianças com os conhecimentos que fazem parte do patrimônio cultural, artístico, ambiental, científico e tecnológico, de modo a promover o desenvolvimento integral de crianças de 0 a 5 anos de idade.

É possível depreender que se procura, por meio dessa definição curricular, "promover e garantir a existência de um currículo que rompa com o assistencialismo, distancie-se da 
escolarização e seja promotor das relações das crianças consigo mesmas, com seus pares, com os adultos e com o mundo" (Carvalho, 2015, p. 467). Assim, a ação docente deve ser promotora de experiências diversificadas, que resultem significativas para as crianças. Nessa concepção, o currículo da Educação Infantil concebe a criança como sujeito histórico e de direitos, detentora e promotora de culturas, que são partilhadas com o professor e as outras crianças a partir de uma escuta atenta.

Por outro lado, em oposição aos princípios da Pedagogia da Infância, bem como à concepção de currículo decorrente dela, pesquisadores e docentes filiados à Pedagogia Histórico-Crítica defendem que a Educação Infantil deve estar fundamentada na transmissão e assimilação dos conteúdos acumulados pela humanidade como forma de humanização da criança (Carvalho, 2019). Desse modo, a escola tem como função apresentar e inserir a criança no mundo pela via da apropriação do conhecimento estabelecido pelas disciplinas sistematizadas e da figura do professor como sendo responsável por esse ensino (Carvalho, 2019). Portanto, a Pedagogia Histórico-Crítica posiciona-se contrária à Pedagogia da Infância, evidenciando o campo de disputas (Carvalho, 2015) no qual se encontra o currículo da Educação Infantil. As concepções sobre currículo são pautadas em "formas particulares de ver e sentir o mundo (nas quais podem ser incluídas as concepções de infância e de sua educação), configuradas nos modos como o conhecimento é organizado" (Carvalho, 2015, p. 467).

Considerando que "a pedagogia se sustenta em uma práxis" (Oliveira-Formosinho; Formosinho, 2019, p. 27), a qual constitui o currículo da Educação Infantil, desenvolvemos, metodologicamente, uma pesquisa de cunho qualitativo (Denzin; Lincoln, 2006). Realizamos entrevistas semiestruturadas (Silva; Carvalho, 2019) com um conjunto de 20 professoras de Educação Infantil ${ }^{2}$ licenciadas em Pedagogia e atuantes nas redes pública e privada de ensino. As questões das entrevistas versaram sobre infância, currículo, didática e docência, almejando a análise das ressonâncias da Pedagogia da Infância nas narrativas de professoras. Todavia, no presente artigo, nosso foco analítico em específico é o mapeamento de princípios da Pedagogia da Infância nas narrativas das professoras sobre o currículo na Educação Infantil.

A partir dos dados gerados com as entrevistas, procedemos à análise do conteúdo (Bardin, 2010) das degravações transcritas. Visando obter uma visão panorâmica do material gerado, fizemos, em um primeiro momento, uma pré-análise, na qual organizamos as informações. Na etapa posterior, realizamos a exploração do material, destacando as reiterações presentes nas entrevistas das professoras a respeito dos aspectos por nós abordados durante as entrevistas. Por fim, através da exploração mais profunda do material, definimos as unidades de análise decorrentes dos eixos infância, currículo, didática e docência. No entanto, no caso deste artigo, escolhemos como fulcro privilegiado de nossas análises o eixo do currículo, com base no qual estipulamos as seguintes unidades analíticas: 1) o currículo emergente; 2) o currículo e a criança protagonista; 3) o currículo e a Pedagogia da Escuta.

Através de tais unidades, evidenciamos reiterativamente ressonâncias (muitas vezes compreendidas de modo naturalizado e sem aprofundamento teórico) da Pedagogia da Infância na concepção de currículo presente nas narrativas das professoras entrevistadas. As análises também indicaram que o modo como as professoras operam o currículo da Educação Infantil é por meio da realização de projetos de trabalho. Isso porque, do ponto de vista delas, com os projetos, podem ser estabelecidas relações entre os saberes e as experiências das crianças, já que esse empreendimento orbita "em torno de problemas ou hipóteses que facilitam às crianças a construção de seus conhecimentos e a transformação procedente dos diferentes saberes disciplinares em conhecimento próprio" (Hernández; Ventura, 1998, p. 61).

Tendo em vista que nenhuma pesquisa é intrinsecamente ética e que toda investigação deve ser permeada por um contínuo processo reflexivo, conforme apontam Gastaldo e McKeever (2002), consideramos oportuno compartilhar os cuidados éticos por nós assumidos enquanto pesquisadores antes, durante e após a produção dos dados de nossa investigação. Inicialmente, a pesquisa foi aprovada pelo Comitê de Pesquisa da Universidade Federal do Rio Grande do Sul (COMPESQ/UFRGS) como constituinte da investigação que estava sendo desenvolvida pelo supervisor do pós-doutoramento. De modo a garantir o 
entendimento da proposta de pesquisa, realizamos um convite e a exposição individual do projeto a cada uma das participantes. Com o aceite das professoras, agendamos uma nova reunião, na qual apresentamos o Termo de Consentimento Livre Esclarecido (TCLE), garantindo a preservação das identidades das participantes, o sigilo dos nomes das instituições, a possibilidade de declinar do aceite de participação em qualquer momento da pesquisa, assim como a posterior leitura das degravações decorrentes das entrevistas.

Após o aceite de todas as participantes e a assinatura do TCLE, efetuamos as entrevistas, priorizando uma perspectiva dialógica (Silva; Carvalho, 2019) durante todo o processo. Em seguida, foram feitas as degravações e a submissão dos textos na íntegra para a leitura das professoras. A partir de então, agendamos um novo encontro, no qual ouvimos as impressões das entrevistadas a respeito das degravações e solicitamos seu aceite final para o uso dos dados gerados. Por fim, seguindo o proposto por Gray (2012), agendamos um encontro com o conjunto de professoras participantes e realizamos a devolutiva da pesquisa com base nos dados produzidos.

Esclarecemos que este artigo está organizado em sete seções. Posteriormente a esta seção introdutória, abordaremos, na segunda seção, uma discussão sobre os documentos curriculares que orientam a Educação Infantil em nosso país e suas relações com os princípios defendidos pela Pedagogia da Infância. Na terceira seção, debateremos a concepção de currículo na Pedagogia da Infância. Na quarta, quinta e sexta seções, apresentaremos as análises a respeito das concepções sobre currículo das professoras entrevistadas. Na última seção, compartilharemos as considerações finais sobre as discussões produzidas no decorrer do artigo.

\section{Os documentos curriculares oficiais da Educação Infantil}

Entrevistador: O que você entende como sendo o currículo na Educação Infantil?

Professora Daiane ${ }^{3}$ : Por mim não precisava de currículo, né? Porque é só uma palavra. A gente trabalha tudo de todas as formas (Professora de Educação Infantil da rede pública, transcrição de entrevista realizada em maio de 2018).

A partir da leitura, é possível evidenciarmos que a professora compreende o currículo de modo amplo e, diga-se, pouco preciso. De fato, a docente desconsidera as discussões conceituais sobre currículo que vem sendo mais intensas na última década e também as contribuições das próprias políticas curriculares de Educação, como é o caso das Diretrizes Curriculares Nacionais de Educação Infantil (DCNEI) (MEC, 2009) e, mais recentemente, da Base Nacional Comum Curricular (BNCC) (Brasil, 2017), a qual contempla a etapa da Educação Infantil.

Conforme a narrativa, na Educação Infantil, os docentes trabalham com tudo de todas as formas, ou seja, a entrevistada defende o pressuposto de que o currículo da Educação Infantil é vasto e repleto de possibilidades. Por outro lado, a entrevistada não manifesta nenhum indicador do que sejam essas possibilidades. Todavia, concordamos que a Educação Infantil, pelas suas particularidades, se difere das demais etapas da Educação Básica, as quais são organizadas a partir de um currículo disciplinar no qual os conteúdos das áreas do conhecimento são apresentados e aprofundados de forma gradativa no decorrer do ano letivo.

Em uma perspectiva disciplinar, o currículo é geralmente entendido como "uma seleção organizada dos conteúdos a aprender, os quais, por sua vez, regularão a prática didática que se desenvolve durante a escolaridade" (Sacristán, 2015, p. 17). Efetivamente, um currículo como sinônimo de lista pré-estabelecida de conteúdos aprofundados na sequência da escolarização não tem relação alguma com as orientações das políticas curriculares nacionais de Educação Infantil. Isso porque a "vivência na escola [da infância] deve ser de aprendizagem e desenvolvimento, autonomia, criatividade, produção de novos saberes, partilha de conhecimentos e de descoberta do mundo" (Callai; Serpa, 2018, p. 149).

Tendo em vista o exposto, cabe-nos indagar: quais são as particularidades do currículo na Educação Infantil? Como a professora define o que será abordado com as crianças? De que modo as práticas pedagógicas docentes põem o currículo em funcionamento? Em que medida as orientações curriculares, como as DCNEI (MEC, 2009) e a BNCC (Brasil, 2017), 
incidem nas concepções docentes sobre currículo? Não temos a pretensão de encontrar respostas para esses questionamentos; entretanto, consideramos oportuno que tais problematizações continuem sendo realizadas para que efetivamente possamos qualificar o trabalho docente na Educação Infantil.

A Educação Infantil tornou-se a primeira etapa da Educação Básica a partir da homologação da Lei de Diretrizes e Bases da Educação Nacional (Brasil, 1996). Desde então, a primeira etapa da Educação Básica vem tendo conquistas, travando embates e superando desafios (Carvalho; Guizzo, 2018).

Ainda há muitas dúvidas e práticas docentes díspares na Educação Infantil - algumas defendendo o ensino dos conteúdos com base nas áreas do conhecimento, como a Pedagogia Histórico-Crítica (Prado; Azevedo, 2012; Arce, 2016); outras com foco nas crianças e nos processos de conhecimento e experimentação do mundo, como é o caso da Pedagogia da Infância. Documentos curriculares oficiais, como as DCNEI (MEC, 2009) e a BNCC (Brasil, 2017), advogam por uma concepção de infância, de criança e de currículo pautada na Pedagogia da Infância. Esses documentos conceituam a criança como sendo um sujeito histórico e de direitos, que constrói a sua identidade pelas interações, relações e práticas cotidianas. Sob esse prisma, existe o argumento de que a criança "brinca, imagina, fantasia, deseja, aprende, observa, experimenta, narra, questiona e constrói sentidos sobre a natureza e a sociedade, produzindo cultura" (MEC, 2009, p. 12).

Isso equivale a declarar que o currículo da Educação Infantil não é visto como uma propriedade docente, mas como "um projeto coletivo, uma obra aberta, criativa e apropriada para o 'aqui-e-agora' de cada situação educativa" (Oliveira, 2011, p. 183). Nessas bases, o currículo da Educação Infantil é compreendido como uma trajetória aberta e flexível "de exploração partilhada de objetos de conhecimento de determinada cultura por meio de propostas diversificadas constantemente avaliadas" (Oliveira, 2011, p. 184-185).

A BNCC (Brasil, 2017), ao procurar operacionalizar as DCNEI (MEC, 2009), reitera as interações e brincadeiras como eixos norteadores do currículo, afirmando que os processos relacionais desenvolvidos durante as brincadeiras caracterizam o cotidiano infantil, contribuindo indefectivelmente com uma miríade de aprendizagens e possibilidades para o desenvolvimento integral das crianças (Brasil, 2017). A partir da observação das brincadeiras entre as crianças e seus pares, é possível identificar a expressão dos afetos, os processos de mediação das frustrações, o modo como as crianças solucionam conflitos e, ainda, a regulação das emoções (Brasil, 2017). Nesse contexto, a professora observa as crianças para poder propor novas situações, questionamentos e propostas que, pautadas nas interações e brincadeiras, contribuam para o desenvolvimento das crianças. Em resumo, a ação pedagógica na Educação Infantil fundamenta-se na observação atenta e na escuta sensível (Pagano, 2017) defendidas pela Pedagogia da Infância. Tendo em vista essas considerações, a BNCC (Brasil, 2017) destaca a indissociabilidade entre o cuidar e o educar na prática pedagógica docente, já que as instituições de Educação Infantil se configuram como espaços de vida coletiva nos quais as crianças aprendem mais sobre si, sobre os outros e o mundo.

Diante disso, é importante esclarecer que a BNCC (Brasil, 2017), objetivando a operacionalização das DCNEI (MEC, 2009), apresenta "aos profissionais da educação um ponto de partida para a organização curricular que atenda o trabalho nas instituições de Educação Infantil” (Vitta; Cruz; Scarlassara, 2018, p. 66). As indicações constantes na BNCC (Brasil, 2017) para a Educação Infantil devem ser pensadas a partir de cada contexto social, incidindo, desse modo, na revisão, discussão e adequação das propostas pedagógicas das escolas.

Diferentemente do que é proposto para as demais etapas da Educação Básica, a BNCC (Brasil, 2017) não estabelece uma organização curricular por áreas de conhecimento para a Educação Infantil, mas indica direitos de aprendizagem e desenvolvimento (conviver, brincar, participar, explorar, expressar e conhecer-se), os quais serão postos em ação na prática docente por meio de um trabalho pautado em cinco campos de experiência. Os campos de experiência são definidos no documento como um modo de organização curricular que contempla as situações da vida cotidiana das crianças e seus saberes, relacionando-os aos conhecimentos que fazem parte de nosso patrimônio cultural (Brasil, 2017). No documento, são apresentados os seguintes campos de experiências: a) o eu, o outro e o nós; b) corpo, 
gestos e movimentos; c) traços, sons, cores e formas; d) escuta, fala, pensamento e imaginação; e) espaços, tempos, quantidades, relações e transformações (Brasil, 2017).

Esses campos de experiências possibilitam que o professor realize um planejamento de contextos, levando em consideração tempos, espaços, materiais, relações e linguagens. Isso implica a compreensão de que o planejamento dos contextos, a partir de uma continuidade dos processos educativos, contemplará os campos de experiência, sempre de modo relacional. Nesse sentido, os campos de experiência trazem possibilidades para a atuação docente, as quais não podem ser estanques ou restritas a determinado campo, como geralmente ocorre no caso de uma organização curricular por disciplinas.

Por outro lado, na contramão da proposta de uma organização curricular pautada em direitos de aprendizagem e campos de experiências para a Educação Infantil, a BNCC (Brasil, 2017) evidencia um descompasso com seus pressupostos ao apresentar uma listagem de objetivos de desenvolvimento e aprendizagem relativos a cada campo de experiência, os quais devem ser alcançados pelas crianças de acordo com a faixa etária em que se encontram. Em tal visão, corre-se o risco de os professores focalizarem apenas objetivos de aprendizagem e desenvolvimento no planejamento de suas práticas e até mesmo de utilizarem essa listagem como indicadora de avaliação das crianças, o que vai de encontro ao que é proposto nas DCNEI (MEC, 2009). Embora a BNCC (Brasil, 2017) destaque que o ritmo de cada criança deve ser levado em consideração, estabelecer listagens de objetivos pode tornar o currículo e o planejamento rígidos e inclusive estigmatizar crianças que não alcancem os resultados esperados com um "rótulo" de incapacidade.

Ademais, contemporaneamente, o mercado editorial tem lançado livros didáticos para professores de Educação Infantil (ou seriam cartilhas?) que indicam atividades e objetivos a serem alcançados em cada campo de experiência, pedagogizando as propostas da BNCC (Brasil, 2017) a partir da difusão de roteiros de práticas pedagógicas que definem e conformam modos de ser professor de Educação Infantil (Carvalho; Silva; Lopes, 2019). Essa difusão de livros didáticos para professores de Educação Infantil contraria a perspectiva de um planejamento de contextos pautado nos direitos de aprendizagem e posto em funcionamento com base nos campos de experiência.

Portanto, é necessário que os professores de Educação Infantil se afastem dos roteiros preestabelecidos e passem a considerar as singularidades das crianças e dos grupos pelos quais são responsáveis. Dito de outra forma, é preciso que os professores compreendam que a "a dimensão que os conhecimentos assumem na educação das crianças pequenas coloca-se numa relação extremamente vinculada aos processos gerais de constituição da criança" (Rocha, 2001, p. 31). Nesses processos, estão em pauta "a expressão, o afeto, a sexualidade, a socialização, o brincar, a linguagem, o movimento, a fantasia, o imaginário e as cem linguagens" (Rocha, 2001, p. 31) das crianças.

Corroborando os argumentos expostos, Pagano (2017, p. 43) defende que o professor, metaforicamente, precisa desenvolver um 'olhar capaz de 'ouvir' os modos de ser, de aprender e de conhecer das crianças”. Nessa direção, argumenta que um currículo construído em parceria com as crianças demanda tempo, observação, disponibilidade, atenção do professor para detectar recorrências nos interesses e oportunidades de construção de conhecimentos, sistematização e avaliação. Ou seja, deve-se investir para que as crianças, "a partir de múltiplas linguagens, se expressem, aprendam, criem e consolidem conceitos" (Pagano, 2017, p. 43) baseadas na vida que inunda seus cotidianos.

\section{A Pedagogia da Infância e o currículo da Educação Infantil}

Entrevistador: O que você entende como currículo na Educação Infantil?

Professora Daniele: Ele é um currículo emergente, que emerge das intenções das crianças, das curiosidades das crianças. Ele não é um currículo fechado. Ele tem que ser um currículo que parta das crianças. E isso é muito mais difícil para as professoras. Porque, para mim, seria muito mais fácil se eu tivesse uma cartilha que me dissesse tudo o que eu tenho que trabalhar durante o ano. Ou, ainda, que tivesse uma lista de datas comemorativas, que interpelassem ali o meu cotidiano. Bom, ok! Eu estava muito certa do que eu iria fazer. Um currículo emergente 
indica pistas, mas não diz o que deve ser realizado. Então, ele é muito mais difícil. E ele acaba sendo muito sério, porque tu tens que entender que o teu objeto de conhecimento é a própria criança, é a centralidade naquela criança; a centralidade do trabalho são as crianças. O currículo vai muito por esse eixo. O Malaguzzi falava muito da pedagogia da escuta, então aqui na escola a gente está trabalhando muito com essa ideia de escutar as crianças e trabalhar com o que elas trazem para nós. E isso não é uma tarefa fácil. Isso não são todos os professores que conseguem. É uma luta com a gente mesmo para desconstruir certas concepções e partir para esse currículo mais aberto (Professora de Educação Infantil da rede pública, transcrição de entrevista realizada em abril de 2018).

A partir da leitura da resposta da participante ao questionamento do pesquisador sobre qual seria a definição de currículo na Educação Infantil, destaca-se que o entendimento expresso pela professora se aproxima (de certo modo) dos princípios defendidos no âmbito da Pedagogia da Infância no que diz respeito aos direitos das crianças e sobretudo a uma compreensão mais plural de currículo. Embora não exista uma referência explícita aos documentos curriculares oficiais como DCNEI (MEC, 2009) e BNCC (Brasil, 2017), reverbera na resposta da professora um vocabulário emergente dos referenciais italianos ${ }^{4}$ de Educação Infantil. Na narrativa, pode-se identificar menção ao currículo emergente, à importância do protagonismo das crianças e à escuta como condição princípio da ação pedagógica. De fato, podemos afirmar que tais aspectos apareceram de forma recorrente em todas as entrevistas realizadas durante a pesquisa, tendo sido, portanto, definidos como unidades de análise.

Ressaltamos que contemporaneamente a Pedagogia da Infância, no âmbito das práticas pedagógicas desenvolvidas pelas professoras, tem recebido, de maneira cada vez mais acentuada, a influência dos referenciais italianos, cujo "vocabulário" vem sendo assimilado pelas professoras de modo naturalizado e sem reflexão teórica. Corroborando o argumento, Horn e Fabris (2017, p. 1114) apontam que essa forma de entender a docência, baseada nos referenciais italianos, tem "reconfigurado o papel do professor como um gerenciador de oportunidades", um professor designer, conforme definem as referidas autoras. Isso porque são "as iniciativas das crianças, seus interesses individuais, seu empreendedorismo particular, que conduzem as ações pedagógicas" (Horn; Fabris, 2017, p. 1114). Afinal, as crianças sempre apresentarão questionamentos e demandas que oportunizarão o planejamento dos contextos?

Sobre isso, consideramos oportuno realizar alguns esclarecimentos. O primeiro diz respeito a como a Pedagogia da Infância, enquanto "conjunto de fundamentos e indicações de ação pedagógica que tem como referência as crianças e as múltiplas concepções de infância em diferentes espaços educacionais" (Barbosa, 2010, p. 1), tem sido colonizada pela narrativa eurocêntrica italiana, a qual não considera as condições sociais, culturais e políticas da América Latina. Não obstante saibamos, por meio da pesquisa de Faria (1999) e posteriormente de Rocha (2001), que, desde a sua emergência, a Pedagogia da Infância em nosso país tenha se inspirado na produção pedagógica italiana sobre Educação Infantil e até mesmo na definição das políticas curriculares para a docência com crianças pequenas, o que nos causa desconforto é a subalternização da produção teórica brasileira na definição dos rumos da educação das crianças e a apropriação dessa abordagem pelos professores sem a devida reflexão.

A difusão dos referenciais italianos vem ocorrendo por meio das traduções de livros que narram práticas pautadas nas pedagogias italianas e principalmente pela crescente ascensão do "mercado pedagógico". Este último, através de seus "profetas educacionais" e cursos de formação continuada, tem apontado, para os professores que atuam nas escolas, lições de como alcançar a "terra prometida" da Educação Infantil a partir das experiências educacionais no norte da Itália.

Talvez a informação que esteja faltando aos professores é que nosso país não faz parte da Europa e que, enquanto América Latina, temos acúmulo suficiente de pesquisas acadêmicas na área da Educação Infantil que podem incidir nos modos de constituirmos uma Pedagogia da Infância mais próxima à nossa realidade. De modo algum somos contrários à perspectiva plural de currículo proposta nos documentos curriculares oficiais de Educação Infantil, assim como não nos opomos em relação às inspirações em pedagogias oriundas de 
outros contextos. O que pontuamos é a necessidade de reflexão docente a respeito da importância de assumirmos a permanente construção de uma Pedagogia da Infância que atenda a nossas demandas enquanto latinos que vivem em um país cuja desigualdade social reverbera diretamente nas condições físicas de nossas instituições de Educação Infantil, na formação docente e no acesso aos bens culturais. Em síntese, não consideramos suficiente o "empiricismo em que a experiência primária do cotidiano, não ampliada, traduz-se em referência central" (Oliveira-Formosinho, 2007, p. 14) na reprodução de modelos pedagógicos. Isso porque tal fato tem repercutido no exercício de uma "espécie de epistemologia da prática no cotidiano das salas de Educação Infantil” (Carvalho, 2014, p. 180).

Prosseguindo a discussão analítica, é oportuno destacar que, após o término da etapa da Educação Infantil, a criança ingressa em outro universo escolar, geralmente dissociado dos princípios da Pedagogia da Infância que pautava a organização curricular anterior. Na narrativa a seguir, por exemplo, a professora, em sua resposta ao questionamento sobre como percebe a transição da Educação Infantil para os anos iniciais do Ensino Fundamental, evidencia sua preocupação com o possível confronto de realidades entre as propostas das etapas.

Entrevistador: Como você percebe a transição das crianças da Educação Infantil para o Ensino Fundamental?

Professora Kelly: Porque aí vem o Ensino Fundamental e parece que são mundos completamente diferentes. Não há uma continuidade. Porque a criança sai de um espaço em que se tem um olhar para a infância, que entende a criança como ser humano potente, que tem o olhar para os interesses dessa criança e depois vai para um universo conteudista (Professora de Educação Infantil da rede pública, transcrição de entrevista realizada em junho de 2018).

A professora entende o ingresso da criança no Ensino Fundamental como uma mudança radical. Em outras palavras, a docente expressa a compreensão de que a criança, ao finalizar a Educação Infantil, sai do contexto proposto pela Pedagogia da Infância para o âmbito dos conteúdos escolares. Conforme a narrativa em análise, com o término da Educação Infantil, (supostamente) não existe mais o entendimento da criança como sendo potente, detentora de direitos e produtora de culturas infantis (Corsaro, 2011) pelas professoras dos anos iniciais do Ensino Fundamental. Dessa forma, a professora ressalta sua apreensão em relação à possível existência de uma pedagogia da transmissão (Oliveira-Formosinho, 2007).

Ratificando o argumento da docente, Oliveira-Formosinho (2007, p. 17) afirma que a escola em geral se baseia em uma pedagogia da transmissão, a qual, centrada "na lógica dos saberes, no conhecimento que quer veicular, resolve a complexidade através da escolha unidirecional dos saberes a serem transmitidos e da delimitação do modo e dos tempos para fazer essa transmissão". Na mesma direção, Hoyuelos (2012, p. 307) critica a escola "instrucionista", a qual insere a criança em uma série de programas e atividades, conteúdos e objetivos "sem levar em consideração a cultura da infância, seus interesses e expectativas".

Considerando o exposto, podemos afirmar que a Pedagogia Histórico-Crítica na Educação Infantil assume essa perspectiva transmissiva ao defender uma concepção de currículo constituída por uma seleção de elementos da cultura global, organizados com configuração de conteúdo para ensino e aprendizagem de "forma lógica, concatenada, articulada horizontal e verticalmente, segundo as características das diferentes idades" (Saviani, 2012, p. 55). Assim, tal Pedagogia sustenta que a Educação Infantil integra a educação escolar e, portanto, deve ter um currículo pautado no ensino e conteúdos escolares (Carvalho, 2019). O currículo, nesse pensamento, é definido como "conjunto de atividades nucleares, intencionalmente planejadas e sistematicamente desenvolvidas, de acordo com as características da faixa etária e com as necessidades e condições concretas das crianças às quais se destinam" (Saviani, 2012, p. 71-72).

Contrapondo-se a esse ponto de vista, Oliveira-Formosinho (2007) argumenta que, por outro lado, a Pedagogia da Infância percebe a criança como ser participante, e não à espera de participação, propondo uma ação "transformativa, que credita a criança com direitos, compreende a sua competência e escuta a sua voz para transformar a ação pedagógica em 
uma atividade compartilhada" (Oliveira-Formosinho, 2007, p. 14). Partindo da indissociabilidade entre cuidar e educar, a Pedagogia da Infância se baseia em dois conceitoschave: a) concepção de infância como construção social; b) entendimento da criança como produto e produtora de cultura, que age e transforma a sua realidade (Gonçalves, 2015). De fato, a Pedagogia da Infância defende "um cotidiano educativo que compreende a criança como uma pessoa com agência, não à espera de ser pessoa, que lê o mundo e o interpreta, que constrói saberes e cultura, que participa como pessoa e como cidadão da vida da família, da escola, da sociedade" (Oliveira-Formosinho, 2007, p. 27).

Como é possível depreender, a criança figura como protagonista na definição de Pedagogia da Infância (Rocha, 2001), sendo entendida como uma parceira do professor no compartilhamento de experiências. Nessa acepção, o objeto não é o conhecimento científico organizado em disciplinas nem o protagonismo do professor como o detentor do saber e o centro da educação. Como lembram Callai e Serpa (2018, p. 148), se concebermos a educação das crianças pequenas a partir de uma concepção conteudista e meritocrática, fruto da atual sociedade, acabaremos por transformar "a escola em uma corrida de obstáculos, em que o conhecimento passa apenas a ser um meio para o exercício incansável de provas, testes, rankings, classificações, seleções, premiações e, claro, exclusões”.

Atualmente o currículo da Educação Infantil se situa em meio a uma arena de disputas (Carvalho, 2015) entre a Pedagogia da Infância e a Pedagogia Histórico-Crítica, a qual não encontra nenhuma ressonância nas políticas curriculares para Educação da Infância, como as DCNEI (MEC, 2009) e a BNCC (Brasil, 2017). A partir da exposição e sobretudo da narrativa da professora analisada anteriormente, consideramos imprescindível alertar que a polarização entre Educação Infantil e Ensino Fundamental não colabora de forma alguma com a continuidade dos processos educativos nem com o avanço das discussões sobre a Educação da Infância nos anos iniciais. Aliás, a transição das crianças da pré-escola para o primeiro ano é temática discutida nas DCNEI (MEC, 2009) e na BNCC (Brasil, 2017), a qual merece atenção e debate nas escolas para que a educação na primeira etapa da Educação Básica não se configure como um espaço sem relação com a etapa subsequente.

Entendemos que seja propício, para avançarmos além de uma discussão polarizada entre as etapas, reiterarmos as especificidades de cada uma delas. A esse respeito, Rocha (2001) esclarece que a Educação Infantil é complementar à educação familiar, tendo, desse modo, como objeto privilegiado as relações educativas desenvolvidas no espaço cotidiano de vida coletiva institucional das crianças.

Nessa perspectiva, conforme indicaram as professoras entrevistadas, o currículo vem sendo operacionalizado na Educação Infantil por meio de projetos de trabalho (Hernandez; Ventura, 1998) emergentes do interesse e da curiosidade das crianças. Estes são projetos baseados em escuta, observação, documentação e interpretação, originando perguntas, hipóteses, algumas respostas e novas perguntas (Pagano, 2017, p. 39), tendo em vista o argumento de que "o conhecimento é relacional, afetivo e emocional".

\section{O currículo emergente na Educação Infantil}

Entrevistador: O que você entende como currículo na Educação Infantil?

Professora Débora: Ele é um currículo emergente, que emerge das intenções das crianças, das curiosidades das crianças (Professora de Educação Infantil da rede privada, transcrição de entrevista realizada em abril de 2018).

Professora Mariana: Nós não temos muitos objetivos, cada turma é uma turma, cada criança é uma criança. Na adaptação, por exemplo, não tem uma coisa certa de como fazer no currículo. Eu vou fazendo do jeito que eu acho que está sendo interessante para aquela criança (Professora de Educação Infantil da rede privada, transcrição de entrevista realizada em abril de 2018).

Professora Suzana: Tu trabalhas algumas coisas que tu tens que trabalhar com eles, mas parte dos interesses deles. Eles vão mostrando os interesses. Aqui na escola a gente trabalha muito sobre isso, e o projeto já nasce do interesse deles. Nosso currículo trabalha com projetos, a gente trabalha com projetos, e dentro do 
projeto a gente vai ampliando o tema que a gente vai trabalhando, conforme o tempo, o que eles trazem e conforme o que tu vai trazendo também (Professora de Educação Infantil da rede privada, transcrição de entrevista realizada em junho de 2018).

Professora Vânia: É o interesse sempre. Em primeiro lugar, temos que atender as crianças. Não adianta fazer um currículo com coisas que não irão chamar a atenção ou não irão surtir muito efeito (Professora de Educação Infantil da rede privada, transcrição de entrevista realizada em junho de 2018).

Professora Teresa: A gente não tem mais trabalhado a questão das datas comemorativas, que antes fazia parte do nosso currículo. No início, eu senti um certo vazio, assim, foi um vazio porque também as crianças esperavam que a gente trouxesse alguma coisa, porque elas nos diziam: "ah, a mana vai se apresentar na outra escola para o dia das mães" ou, sei lá, "o coelhinho vai me trazer ovos", então eles nos traziam essas informações. Então, para não deixar totalmente e não deixar passar batido, a gente teve que levar em conta todas as intervenções das crianças (Professora de Educação Infantil da rede pública, transcrição de entrevista realizada em abril de 2018).

A centralidade dos interesses das crianças na constituição de um currículo emergente é reiterada pelas professoras durante as entrevistas. Nesse contexto, interesse se torna uma palavra de ordem. São os interesses das crianças que indicam os rumos que irão tomar os projetos de trabalho propostos pelas docentes. A noção de interesse é assumida como princípio da prática docente (Carvalho; Guizzo, 2016). Em tal direção, as professoras "consideram as crianças como base das ações educativas, em torno das quais as propostas devem ser planejadas e operacionalizadas" (Carvalho; Guizzo, 2016, p. 217).

Nas narrativas transcritas, por exemplo, evidenciamos que apenas uma das docentes aborda a necessidade de definição de objetivos, os quais posteriormente podem ser reformulados, tendo em conta o atendimento das demandas que surgem no contexto educativo. Isso implica afirmar que as professoras compreendem que o currículo emerge dos interesses das próprias crianças, pois são elas que estabelecem, a partir de seus questionamentos, o que será desenvolvido e por quanto tempo. Nesse contexto, até mesmo "a organização curricular monocultural por datas comemorativas, historicamente presente na Educação Infantil” (Maia, 2013, p. 137), cede espaço a um outro modo de entender o currículo.

As narrativas das entrevistadas abordam a noção de currículo emergente, mesmo sem apresentar uma conceituação teórica a respeito dele. O conceito de currículo emergente é elaborado no contexto dos referenciais italianos de Educação Infantil, como esclarecem Gandini e Goldhaber (2002, p. 152): esse "currículo é constituído em decorrência das observações dos professores sobre as ideias e os interesses das crianças, mas também é elaborado conforme o que os professores de crianças constroem juntos". De acordo com a proposta de um currículo emergente, os professores definem objetivos educacionais gerais e não para cada projeto desenvolvido. Em razão disso, os docentes "formulam hipóteses sobre o que poderá ocorrer, com base em seu conhecimento das crianças e das experiências anteriores" (Rinaldi, 1999, p. 107). Isso reforça o entendimento de que, a partir das hipóteses levantadas, os professores "elaboram objetivos flexíveis e adaptados às necessidades e interesses das crianças” (Rinaldi, 1999, p. 107).

Dessa forma, o currículo emergente se opõe a uma organização curricular fundamentada no ensino de conteúdo decorrente de áreas de conhecimento ou ainda de datas comemorativas. Como já sinalizamos, o currículo emergente é constituído a partir das demandas das crianças e da intencionalidade pedagógica do professor. Assim, fica visível que o professor concebe sua identidade profissional no processo de construção do conhecimento com as crianças, "elaborando hipóteses, ouvindo com o coração e a cabeça, oferendo contextos ricos, apresentando perguntas geradoras, tornando-se porta-voz dos direitos e desejos das crianças" (Pagano, 2017, p. 43).

Entretanto, percebemos incertezas nas narrativas compartilhadas, talvez em decorrência de uma compreensão mais densa teoricamente sobre a concepção de currículo emergente. Não nos parece que o proposto nos referenciais italianos é que se chegue a uma turma sem 
um planejamento para o acolhimento das crianças. Ao conhecer as crianças, o cotidiano irá se desenhando; todavia, são as professoras que detêm o conhecimento e a experiência pedagógica necessária para desenvolver o currículo na prática.

O ponto que levantamos com base nas narrativas é a aparente falta de intencionalidade educativa nas práticas docentes com as crianças. Assim, consideramos oportuno indagar: onde se encontra a intencionalidade educativa da prática docente exercida pelas professoras entrevistadas? Tendo em vista que um currículo emergente não retira o estabelecimento de objetivos norteadores dessa ação (Rinaldi, 1999), não estamos de acordo com o "apagamento" da ação docente. Isso porque, conforme exposto na BNCC (Brasil, 2017, p. 38), existe "a necessidade de imprimir intencionalidade educativa às práticas pedagógicas na Educação Infantil, tanto na creche como na pré-escola". Tal intencionalidade "consiste na organização e proposição, pelo educador, de experiências que permitam às crianças conhecer a si e ao outro e de conhecer e compreender as relações com a natureza, com a cultura e com a produção científica" (Brasil, 2017, p. 39).

Posicionando-se de forma contrária ao currículo emergente, Prado e Azevedo (2012) defendem que o currículo na Educação Infantil deve ser fundamentado em uma teoria histórico-cultural pautada no ensino de "conhecimentos historicamente produzidos pela humanidade" (Prado; Azevedo, 2012, p. 49). A crítica das autoras está direcionada à compreensão da Pedagogia da Infância sobre a natureza da Educação Infantil, a qual está baseada no conceito de educação, e não de ensino. É nesse sentido que Rocha (2001), ao explicar a diferença entre educar e ensinar, declara que prefere o uso do termo educar na Educação Infantil. Para a autora, educar é mais amplo que ensinar: educar contempla as especificidades da educação das crianças pequenas, incluindo todos os processos de aprendizagem, descobertas e relações que são desenvolvidas no contexto de vida coletiva da Educação Infantil.

A contribuição de Rocha (2001) evidencia que existe ponto de contato entre as concepções de currículo das professoras entrevistadas e o modo como, no âmbito da Pedagogia da Infância, se entende a organização curricular. A proximidade reside em uma visão mais abrangente de currículo, a qual contempla as experiências das crianças. Por outro lado, a concepção das professoras entrevistadas se distancia da perspectiva nos documentos curriculares legais da Educação Infantil quando as professoras não demonstram uma intencionalidade educativa. Enfatizamos que são as professoras que realizarão a articulação entre as experiências das crianças e os conhecimentos de ordem cultural, social, tecnológica, etc., e, portanto, que "parte do trabalho do educador é refletir, selecionar, organizar, planejar, mediar e monitorar o conjunto de práticas e interações, garantindo a pluralidade de situações que promovam o desenvolvimento pleno das crianças" (Brasil, 2017, p. 39).

\section{O currículo e a criança protagonista}

Entrevistador: O que você entende como currículo na Educação Infantil?

Professora Kelly: Não é assim, porque a gente parte dos interesses, agora tudo algumas pessoas se assustam um pouco com essa criança-protagonista - não quer dizer que a gente não faz nada. Pelo contrário, a gente tem uma sobrecarga muito maior, assim, de estar atento a essas questões (Professora de Educação Infantil da rede pública, transcrição de entrevista realizada em junho de 2018).

Professor Dênis: [...] tu trabalhas algumas coisas que tu tens que trabalhar com eles, mas parte dos interesses deles. Eles vão mostrando os interesses. Aqui na escola a gente trabalha muito sobre isso e o projeto já nasce do interesse deles. Nosso currículo trabalha com projetos, a gente trabalha com projetos, e dentro do projeto a gente vai ampliando o tema que a gente vai trabalhando, conforme o tempo, o que eles trazem e conforme o que tu vais trazendo também (Professor de Educação Infantil da rede pública, transcrição de entrevista realizada em junho de 2018).

Entrevistador: Quais são as suas intenções ao pensar uma proposta para o seu grupo? 
Professora Débora: É um conjunto. Levo em conta o interesse deles; isso para mim é essencial. Tu trabalhando com o desejo, tu tens um plano de aula maravilhoso. Eu considero o que é necessário para eles para estimular ainda mais o desenvolvimento deles. Eu considero assuntos da atualidade que estão circulando por eles, pelas famílias. Não trabalho tão aprofundado, mas são coisas que eu preciso trabalhar com eles. A essência do trabalho é o que as crianças estão trazendo (Professora de Educação Infantil da rede privada, transcrição de entrevista realizada em maio de 2018).

O protagonismo das crianças é a tônica das entrevistas. $\mathrm{O}$ argumento utilizado pelas professoras é que o protagonismo das crianças é condição imprescindível para a operacionalização do currículo na Educação Infantil. Em tal direção, consideramos propício esclarecer que "a palavra 'protagonismo' tem origem no latim: protos quer dizer principal e agonistes significa lutador" (Guizzo; Balduzzi; Lazzari, 2019, p. 274), ou seja, "ser protagonista significa ter papel de destaque num acontecimento, área ou situação" (Guizzo; Balduzzi; Lazzari, 2019, p. 274). Assim, o protagonismo das crianças está relacionado indefectivelmente à sua participação na vida institucional, "bem como na (re)solução de situações e de problemas que emergem no cotidiano em que estão inseridas, sob a supervisão ou orientação dos adultos" (Guizzo; Balduzzi; Lazzari, 2019, p. 274).

De modo algum se nega a ação docente. Isso porque será a professora quem irá planejar estratégias e oportunizar situações em que as crianças possam efetivamente participar do cotidiano institucional e exercer seu protagonismo nos processos de tomada de decisão quanto aos fatos que lhes dizem respeito. Trata-se da intencionalidade pedagógica de um professor que observa, que pesquisa, que escuta as crianças, mas também propõe, planeja, inventa, cria, desperta e amplia interesses e conhecimentos. O professor ouve as curiosidades, as hipóteses das crianças e, a partir delas, propõe investigações e descobertas (Pagano, 2017). Particularmente em relação a esse tema, cabe lembrar que "o professor deve estabelecer um relacionamento pessoal com cada criança e basear este relacionamento no sistema social da escola" (Rinaldi, 1999, p. 110).

Uma das entrevistadas, inclusive, esclarece em sua resposta que entender a criança como protagonista não significa que o professor não faz nada; ao contrário, ao não ter uma lista de conteúdo a ser seguida, a professora tem que partilhar com a criança esse currículo. Pagano (2017, p. 31) reitera essa ideia ao afirmar que a ação docente "não é simplesmente deixar fluir o cotidiano, mas parar para questionar o que está acontecendo, tentando distinguir o que está vendo", para então planejar contextos ricos e provocativos que mobilizem as ações das crianças. O planejamento, em tal perspectiva, "permite o intercâmbio e a comunicação entre os três protagonistas e parceiros interativos da escola: crianças, educadores e famílias" (Rinaldi, 1999, p. 109).

O currículo da Educação Infantil baseado no protagonismo das crianças não está pautado apenas nos interesses das crianças; encontra-se alicerçado na atuação do professor em parceria com as famílias. O professor desempenha um papel fundamental, no planejamento de estratégias que sejam mobilizadoras das questões trazidas pelas crianças durante o decurso da realização dos projetos. Da mesma forma, é o professor que, ao observar e conhecer a turma, deve propor desafios, novos conhecimentos e outras possibilidades de desenvolvimento da autonomia das crianças. Como lembram Guizzo, Balduzzi e Lazzari (2019, p. 274), "para que esse protagonismo ocorra é imprescindível que uma certa liberdade (atrelada às ideias de autonomia e independência) seja colocada em prática". Nesse contexto, as famílias também desempenham um papel fundamental na construção do currículo. Em um diálogo aberto, escola, professores e família pensam estratégias que mobilizem o espírito investigativo das crianças.

É possível perceber que, pelo menos no dito pelas professoras, o currículo (supostamente) opera como o desencadeador do protagonismo das crianças. A partir da identificação e do acolhimento dos interesses das crianças, desenvolvem-se projetos nos quais, segundo as professoras, se oportuniza que as crianças exerçam seu protagonismo. Desse modo, as colocações das entrevistadas ratificam o argumento de que a proposta de um currículo emergente parte da "imagem das crianças como [sendo] ricas, fortes e poderosas, cuja ênfase é colocada em vê-las como sujeitos únicos com direitos, em vez de simplesmente 
com necessidades" (Rinaldi, 1999, p. 108). O protagonismo da criança é compartilhado com os professores e com as famílias. Isso porque se entende que a aprendizagem é decorrente dos processos de intercâmbio social, no qual "as crianças tornam-se agentes ativos em sua socialização, construída em parceria com seus companheiros” (Rinaldi, 1999, p. 110).

Embora possamos localizar a emergência da noção de interesse, assim como a de protagonismo da criança, nos pressupostos dos teóricos da Escola Nova (Carvalho; Guizzo, 2016), "atualmente é possível afirmar que esse conceito ressurge com bastante força, principalmente em referenciais educacionais italianos" (Guizzo; Balduzzi; Lazzari, 2019, p. 274), os quais têm repercutido na constituição da Pedagogia da Infância em nosso país. Nesse sentido, é interessante registrarmos também que críticas têm sido feitas a tal perspectiva no que diz respeito ao "apagamento" do papel docente nesse cenário, tendo em vista a centralidade dos interesses das crianças e o correlato protagonismo delas na definição do currículo na Educação Infantil.

A crítica é que as crianças têm ocupado um espaço central "nos processos educacionais, sendo protagonistas de suas ações, e os adultos [têm ocupado], talvez, um lugar mais periférico, de coprotagonistas e gerenciadores das ações infantis" (Horn; Fabris, 2017, p. 1113), cuja preocupação está relacionada à "organização dos espaços e registro do que as crianças escolheram fazer na rotina escolar" (Horn; Fabris, 2017, p. 1113). Reiterando essa crítica, Prado e Azevedo (2012, p. 49) afirmam que considerar o professor da Educação Infantil como "mero protetor dos direitos da criança e a escola como um espaço de vivência, como um lugar livre" repercute na descaracterização da função social da escola enquanto instituição educacional.

Sem dúvida alguma, é importante mantermos a reflexão, problematizando as leituras (muitas vezes apressadas e pouco densas) realizadas dos referenciais italianos, bem como os modos como tais teorizações são compreendidas pelas professoras no contexto de suas práticas. Afinal, é sempre válido questionar: o que as docentes nomeiam como protagonismo das crianças? Participação e protagonismo são tomados como sinônimos? A participação das crianças incide na proposta pedagógica das instituições? Quais estratégias docentes garantem o protagonismo das crianças? As crianças têm um papel de destaque no cotidiano institucional, o qual efetivamente repercute no projeto pedagógico?

\section{Currículo e Pedagogia da Escuta}

Entrevistador: Quais estratégias você utiliza para planejar para o seu grupo?

Professora Mariana: Observação, flexibilidade, a fala das crianças, o que vem deles, às vezes, o interesse dos pais... alguns pais perguntam se dá para trabalhar isso ou aquilo. Se vem algum pai e me conta que a criança está muito interessada em alguma coisa, tento ouvir. Acho que é bem isso: observação, flexibilidade, a fala deles, acho que também um pouco do currículo, que para aquela faixa etária é importante, e um pouco do que a escola nos traz, da ajuda que a gente recebe e o que tá precisando para aquela idade (Professora de Educação Infantil da rede privada, transcrição de entrevista realizada em abril de 2018).

Entrevistador: O que você entende como currículo na Educação Infantil?

Professora Daniele: São os nossos projetos e as coisas que as crianças trazem para trabalharmos. Páscoa nós não trabalhamos, Natal nós não trabalhamos... a gente trabalha o que está na cultura das crianças (Professora de Educação Infantil da rede pública, transcrição de entrevista realizada em abril de 2018).

Professora Carla: Eu acho que é tudo, sabe? Desde o chegar na escola, escutar, entender a criança. Desde a mamadeira que a gente alcança, a forma como você pega a criança no colo, dá a mamadeira, a quantidade de alimento que você coloca dentro da boca da criança. Eu acho que o currículo perpassa todos os momentos da escola (Professora de Educação Infantil da rede pública, transcrição de entrevista realizada em abril de 2018). 
Professora Darlene: Eu acho que o currículo é tudo. Desde a tua proposta, as propostas que você apresenta para as crianças, os materiais. Eu acho que tudo isso faz parte do currículo, como tu organiza a tua sala, como tu dispõe os materiais na tua sala. E nos bebês, tudo, né? Como tu escuta, acolhe e entende as tuas famílias, como tu faz a troca de fraldas, acho que tudo isso faz parte do currículo (Professora de Educação Infantil da rede pública, maio de 2018).

Como é possível depreender da leitura das narrativas, a noção de Pedagogia da Escuta está intimamente relacionada à de currículo emergente e de protagonismo da criança. A Pedagogia da Escuta, na perspectiva dos referenciais italianos, é vista como uma arte para entender a cultura infantil, a qual compreende a forma de as crianças pensarem, agirem, perguntarem, teorizarem e desejarem (Hoyuelos, 2012). Por essa razão, a escuta não é somente ouvir o que as crianças têm a dizer, mas utilizar todos os sentidos para perceber as relações que as crianças estabelecem com o mundo (Hoyuelos, 2012).

Reiterando o exposto, Arcuri (2017, p. 89-90) argumenta que escutar as crianças implica "respeitar as formas que elas usam para se comunicar, utilizando diferentes recursos, gestos, emoções, desenhos, brincadeiras - e reconhecer os modos com que conferem sentido as suas experiências". Para tanto, a "escuta precisa ser sensível aos padrões que nos conectam aos outros" (Rinaldi, 2016, p. 236). Os processos de escuta são complexos, abertos, dinâmicos e interconectados: quem escuta também fala e é ouvido a partir de um processo dialógico. Pode-se afirmar que a "pedagogia da escuta não é apenas uma pedagogia para a escola, mas também uma atitude para a vida, na qual se assume a responsabilidade pelo que é compartilhado" (Rinaldi, 2016, p. 236).

Desde essa perspectiva, Rinaldi (2014) apresenta uma série de elementos que compõem a Pedagogia da Escuta. Conforme a referida autora, escutar envolve disponibilidade e sensibilidade. A escuta surge de uma curiosidade, de um desejo, de uma dúvida, de uma emoção e exige tempo, silêncios, valorização da diferença e a revisão de preconceitos e julgamentos. Nesse processo, crianças, professores e famílias aprendem pela construção de narrativas, hipóteses, trocas e diálogos. Dessa maneira, a escuta pode ser considerada um processo complexo que coloca todos os envolvidos no processo educacional em um movimento de aprendizado. Ora, é "a capacidade de escuta e expectativa recíproca, que permite a comunicação e o diálogo, é a qualidade da mente e da inteligência humana que está claramente presente nas crianças pequenas" (Rinaldi, 2016, p. 235). Ou seja, somente podemos conhecer a cultura infantil (Corsaro, 2002) através de uma escuta atenta.

É nesse sentido que a Pedagogia da Infância se fundamenta nos processos de “observação, escuta e negociação" (Oliveira-Formosinho, 2007). Eis a razão pela qual a "observação é [vista como] um processo contínuo, pois requer o conhecimento de cada criança individual, no seu processo de aprendizagem e de desenvolvimento" (OliveiraFormosinho, 2007, p. 28). A escuta, por sua vez, é condição indispensável para se aproximar das crianças e ouvir suas contribuições no processo relacional de construção do conhecimento. Por conseguinte, a negociação consiste na "participação guiada da classe na co-definição do planejamento curricular" (Oliveira-Formosinho, 2007, p. 28).

Os processos de escuta, por serem complexos, demandam tempo, já que "a escuta é mais do que o simples ato de ouvir a fala do outro" (Arcuri, 2017, p. 43). Como se pode notar, a partir da leitura das narrativas das professoras entrevistadas, não se evidencia a ideia de negociação, como, por exemplo, no caso da participação das crianças no planejamento. Todavia, uma das professoras afirma que observa as crianças e as escuta, em consonância com o que eventualmente a família traz e com o que a coordenação da escola demanda. Na mesma direção, outra docente problematiza o currículo organizado por datas comemorativas para reafirmar que trabalha o que está na cultura das crianças, a partir do processo de escuta delas. Em relação ao exposto, sentimos ausência, na resposta das professoras, do modo como articulam a escuta das crianças com a constituição do currículo na Educação Infantil, já que, conforme aponta Rinaldi (2016), para que tal processo ocorra, o professor precisa saber observar, documentar e interpretar os percursos das crianças.

Após a leitura das respostas das professoras, mais uma vez estaríamos diante do que Oliveira-Formosinho (2007) denomina empiricismo de um modelo pedagógico? As professoras estariam baseadas apenas em crenças, valores e princípios, despidos da análise 
"das práticas e do uso de saberes e teorias, os quais constituem o movimento triangular de constituição da Pedagogia [da Infância]” (Oliveira-Formosinho; Formosinho, 2019, p. 27)?

\section{Considerações finais}

[...] a pedagogia sustenta-se em uma práxis, ou seja, em uma ação impregnada de teoria e sustentada por um sistema de crenças. Uma vez que a práxis é o lócus da pedagogia, ela se torna o lócus para o desenvolvimento do conhecimento pedagógico (Oliveira-Formosinho; Formosinho, 2019, p. 27).

Neste artigo, buscamos refletir sobre as ressonâncias da Pedagogia da Infância nas narrativas sobre o currículo da Educação Infantil de professoras das redes pública e privada da cidade de Porto Alegre e da região metropolitana. A partir das discussões desenvolvidas no artigo, consideramos oportuno compartilhar o que temos entendido, com base na pesquisa, como conquistas da Educação Infantil em relação ao currículo e suas ressonâncias na prática docente. Além disso, é importante pontuar algumas problematizações relativas ao que temos denominado "colonização" da Pedagogia da Infância em nosso país e, por fim, apresentar alguns desafios que ainda temos que enfrentar para que efetivamente se possa pensar em uma organização curricular que contemple nossas demandas enquanto brasileiros.

Inicialmente, destacamos a relevância das conquistas que a Educação Infantil alcançou em nosso país por meio do reconhecimento da Educação Infantil como direito das crianças (Carvalho; Guizzo, 2018). Isso repercutiu indefectivelmente na constituição de uma Pedagogia da Infância (Faria, 1999; Rocha, 2001; Barbosa, 2010; Carvalho, 2019) e na correlata proposição de políticas curriculares como as Diretrizes Curriculares Nacionais de Educação Infantil (DCNEI) (MEC, 2009), reafirmadas (de certo modo) pela Base Nacional Comum Curricular (BNCC) (Brasil, 2017). Especificamente em relação às DCNEI (MEC, 2009), consideramos extremamente significativo o destaque do documento ao "entendimento do currículo como conjunto de práticas, da criança vista como centro do planejamento, da perspectiva de desenvolvimento integral das crianças" (Carvalho, 2015, p. 472), com base nas interações e brincadeiras como eixos norteadores do currículo.

A ampliação do conceito de currículo, sem dúvida alguma, tem implicado uma mudança paradigmática do que se entende por docência na Educação Infantil. Por conseguinte, a BNCC (Brasil, 2017), a partir da indicação de direitos de desenvolvimento e aprendizagem, assim como de campos de experiências, excetuando-se a ortodoxa listagem de objetivos de desenvolvimento e aprendizagem de que vem acompanhada, é também uma conquista no campo da Educação Infantil (Carvalho; Guizzo, 2018). Tais conquistas certamente têm contribuído para a constituição da Pedagogia da Infância em nosso país.

Por outro lado, conforme sinalizado em nossa pesquisa, com base nas entrevistas realizadas, bem como nas investigações de Carvalho e Guizzo (2016) e de Horn e Fabris (2017), temos percebido um processo cada vez mais acentuado de "colonização" do currículo e, de modo correlato, das práticas docentes na Educação Infantil a partir dos referenciais italianos. A Pedagogia da Infância, preconizada por Faria (1999) e Rocha (2001), a qual reivindicava um olhar atento para a produção da pesquisa acadêmica no campo da Educação Infantil produzida no Brasil, se torna gradualmente mais distante.

Como foi possível notar nas narrativas das entrevistadas, o empiricismo (OliveiraFormosinho, 2007) baseado nos referenciais italianos tem um papel de destaque, destituído de entendimento teórico e (re)contextualização no âmbito das práticas desenvolvidas. Observamos, com as análises empreendidas, que o currículo na Educação Infantil é compreendido pelas professoras como sendo emergente do conhecimento e da observação. Nesse contexto, as crianças são vistas como protagonistas, detentoras de direitos e produtoras de culturas, argumento que não exclui a participação das famílias nesse processo. Para tanto, de acordo com as entrevistadas, o currículo na Educação Infantil fundamenta-se na escuta atenta às crianças, aos seus anseios, aos seus desejos e às suas curiosidades.

É nesse sentido que questionamos os modos como as professoras têm se apropriado desses referenciais italianos em nosso país, tendo em vista a diversidade de realidades que vivenciamos no território nacional. No momento em que as experiências de outros países deixam de ser inspirações para assumirem um caráter muitas vezes mandatório, devemos 
parar e refletir sobre os modos como estamos produzindo Pedagogia. Afinal, não seria possível à Pedagogia da Infância brasileira também buscar inspirações nas experiências educacionais da América Latina, as quais têm muitos pontos de contato com o que vivenciamos no contexto de nossas instituições públicas de Educação Infantil? Ora, talvez seja mais honesto admitirmos que a entrada dos referenciais italianos em nosso país tem movimentado o "mercado pedagógico" das formações continuadas e da produção editorial em larga escala endereçadas aos professores de Educação Infantil.

Por fim, cabe destacar alguns desafios importantes a serem enfrentados no âmbito do currículo da Educação Infantil para que possamos continuar pensando em uma Pedagogia da Infância. Dentre esses desafios, salientamos:

a) a necessidade de a comunidade epistêmica da Educação Infantil (a qual não é constituída apenas por pesquisadores, mas também pelos docentes que efetivamente exercem a docência nas instituições) realizar uma crítica interna do processo de "colonização" da Pedagogia da Infância;

b) a relevância de nós pesquisadores e dos docentes que se situam no campo da Pedagogia da Infância sabermos acolher as problematizações tanto dos estudos críticos (Prado; Azevedo, 2012; Arce, 2016) como dos pós-críticos (Horn; Fabris, 2017) para seguirmos reconfigurando nossas práticas;

c) a compreensão de que "não existem pedagogias destituídas de relações de poder" (Carvalho, 2019);

d) a problematização do "militantismo, o clubismo, o discursivismo, o teoricismo, o didatismo e o ritualismo" (Oliveira-Formosinho, 2017, p. 31) que tem marcado a formação de professores de Educação Infantil em nosso país a partir de inspirações em referenciais teóricos eurocêntricos;

e) a recuperação da figura do docente nas práticas pedagógicas, bem como a intencionalidade educativa na Educação Infantil, já que defendemos arduamente o reconhecimento de nossa profissão enquanto professores e não cuidadores, pajens, babás ou seus correlatos;

f) a compreensão, enquanto professores, de que não existe um "modelo" de professor, mas que somos nós que constituímos modos de exercício da docência, sempre passíveis de reinvenção.

Pelos motivos expostos, entendemos que os desafios compartilhados ratificam nossa defesa pela consolidação de uma Pedagogia da Infância que reconheça as crianças, os professores e o nosso contexto político, econômico e social de acesso à educação e de formação de professores. Afinal, sempre é tempo de dizermos não aos reducionismos (Oliveira-Formosinho, 2007) que muitas vezes incidem nas concepções curriculares dos professores que atuam na Educação Infantil.

\section{Notas}

1. Pesquisa intitulada "Práticas das Pedagogias da Infância a partir de narrativas de professoras de Educação Infantil", desenvolvida no período de 12/03/2018 a 09/12/2019 na Faculdade de Educação da Universidade Federal do Rio Grande do Sul (FACED/UFRGS), sob a supervisão do Prof. Dr. Rodrigo Saballa de Carvalho (PPGEdu/UFRGS na Linha de Pesquisa: Estudo das Infâncias). Ademais, tal investigação esteve vinculada à pesquisa "A Pedagogia da Infância em discurso: emergência, embates e reinvenções do conceito na prática de pesquisa na Educação Infantil”, coordenada pelo supervisor do pós-doutoramento no período de 12/03/2016 a 09/12/2019.

2. Durante o decorrer do primeiro semestre do ano de 2018 , realizamos entrevistas individuais com um conjunto de 20 professoras. As entrevistas ocorreram nos locais previamente agendados pelas participantes e tiveram em torno de uma hora de duração. É válido esclarecer que, das profissionais que participaram de nossa pesquisa, dez atuavam como professoras da rede pública e outras dez como docentes da rede privada de ensino da cidade de Porto Alegre e da região metropolitana. Por essa razão, tendo em vista contemplar uma maior abrangência da atuação docente em nossa investigação, entrevistamos professoras que trabalhavam com crianças de 0 a 3 anos (creche) e de 4 a 6 anos (préescola).

3. Tendo em vista a preservação da identidade das professoras participantes da pesquisa, todos os nomes são fictícios. Durante a pesquisa, foi solicitado que cada uma das professoras escolhesse um nome para ser utilizado posteriormente no relatório de pesquisa e publicações.

4. Inspirados em Horn e Fabris (2017), utilizamos a expressão "referenciais italianos" para nos referirmos ao conjunto de obras sobre práticas pedagógicas, traduzidas e veiculadas em nosso país. 


\section{Referências}

ARCE, Alessandra. Como pensar e organizar o trabalho pedagógico na Educação Infantil?: contribuições da teoria histórico-cultural. In: PAGNONCELLI, Cláudia; MALANCHEN, Júlia; MATOS, Neide Silveira Duarte. $\mathrm{O}$ trabalho pedagógico nas disciplinas escolares: contribuições a partir dos fundamentos da pedagogia histórico-crítica. Campinas, SP: Armazém do Ipê, 2016. p. 95-110.

ARCURI, Priscila Abel. A participação é um convite e a escuta um desafio: estudo sobre a participação e escuta de crianças em contextos educativos diversos. 2017. 99 f. Dissertação (Mestrado em Educação) Universidade de São Paulo, São Paulo, SP, 2017.

BARBOSA, Maria Carmen Silveira. Pedagogia da infância. In: OLIVEIRA, Dalila Andrade; DUARTE, Adriana Cancella; VIEIRA, Lívia Fraga. Dicionário: trabalho, profissão e condição docente. Belo Horizonte: UFMG/Faculdade de Educação, 2010. p. 01-03.

BARDIN, Laurence. Análise de conteúdo. 4. ed. Lisboa: Loyola. 2010.

BRASIL. Lei n. ${ }^{\circ}$ 9.394, de 20 de dezembro de 1996. Estabelece as diretrizes e bases da educação nacional. Diário Oficial da União, Brasília, DF, 23 dez. 1996.

BRASIL. Ministério da Educação. Base Nacional Comum Curricular. Brasília, DF: MEC, 2017.

CALLAI, Cristiana; SERPA, Andréa. Tensionando currículos na educação infantil. Teias, Rio de Janeiro, v. 19, n. 14, p. 148-149, jul./set. 2018.

CARVALHO, Rodrigo Saballa. Análise do discurso das diretrizes curriculares nacionais de educação infantil: currículo como campo de disputas. Educação, Porto Alegre, v. 38, n. 3, p. 466-476, set./dez. 2015.

CARVALHO, Rodrigo Saballa. Aprendizagem e formação docente: uma analítica do discurso do ProInfantil. Linhas Críticas, Brasília, DF, v. 20, n. 41, p. 167-187, jan./abr. 2014.

CARVALHO, Rodrigo Saballa. Práticas de governamento em livros de formação de professores de educação infantil: sensibilidades, disposições e conscientizações em discurso. Educação Temática Digital, Campinas, v. 21, n. 1, p. 84-104, jan./mar. 2019.

CARVALHO, Rodrigo Saballa; GUIZZO, Bianca Salazar. Interesse das crianças, pedagogia de projetos e metacognição: a arte de governar a docência na Educação Infantil. Caderno de Pesquisa, São Luís, v. 23, número especial, p. 212-226, set./dez. 2016.

CARVALHO, Rodrigo Saballa; GUIZZO, Bianca Salazar. Políticas de Educação Infantil: conquistas, embates e desafios na construção de uma Pedagogia da Infância. Revista Educação Pública, Cuiabá, v. 27, n. 66, p. 771-791, set./dez. 2018.

CARVALHO, Rodrigo Saballa; SILVA, Marcelo Oliveira; LOPES, Amanda Oliveira. A pedagogização da docência na Educação Infantil. In: SEMINÁRIO BRASILEIRO DE ESTUDOS CULTURAIS, 8., SEMINÁRIO INTERNACIONAL DE ESTUDOS CULTURAIS E EDUCAÇÃO, 5., 2019, Canoas. Anais... Canoas: PPGEDU, 2019.

CORSARO, William. Sociologia da infância. 2. ed. Porto Alegre: Artmed, 2011.

DENZIN, Norman K.; LINCOLN, Yvonna S. Introdução: a disciplina e a prática da pesquisa qualitativa. In: DENZIN, Norman K. et al. (Orgs.). O planejamento da pesquisa qualitativa: teorias e abordagens. 2. ed. Porto Alegre: Artmed, 2006. p. 15-41.

FARIA, Ana Lúcia Goulart. Educação pré-escolar e cultura: para uma pedagogia da educação infantil. Campinas, SP: Unicamp; São Paulo, SP: Cortez, 1999.

GANDINI, Lella; GOLDHABER, Jeanne. Duas reflexões sobre a documentação. In: GANDINI, Lella; EDWARDS, Carolyn (Orgs.). Bambini: a abordagem italiana na Educação Infantil. Porto Alegre: Artes Médicas, 2002. p. 150-169.

GASTALDO, Denise; MCKEEVER, Patrícia. Investigación qualitativa intrinsecamente ética? In: MERCADO, Francisco J.; GASTALDO, Denise; CALDERÓN, Carlos (Orgs.). Investigación cualitativa en salud en Iberoamérica: métodos, análisis y ética. Guadalajara, México: Universidad Autônoma de Nuevo León; Servício Vasco de Salud Osakidetza, 2002. p. 475-479.

GONÇALVES, Jacqueline da Silva. Pedagogia da educação infantil: avanços, desafios e tensões. Curitiba: Apris, 2015.

GRAY, David E. Pesquisa no mundo real. 2. ed. Porto Alegre: Penso, 2012.

GUIZZO, Bianca Salazar; BALDUZZI, Lucia; LAZZARI, Arianna. Protagonismo Infantil: um estudo no contexto de instituições dedicadas à primeira infância em Bolonha. Educar em Revista, Curitiba, v. 35, n. 74, p. 271-289, mar./abr. 2019.

HERNÁNDEZ, Fernando; VENTURA, Montserrat. A organização do currículo por projetos de trabalho: o conhecimento é um caleidoscópio. 5. ed. Porto Alegre: Artmed, 1998.

HORN, Cláudia Inês; FABRIS, Elí Henn. Registro docente contemporâneo: infância e docência em tempos digitais. Educação e Realidade, Porto Alegre, v. 42, n. 3, p. 1103-1122, jul./set. 2017.

HOYUELOS, Alfredo. La ética en el pensamento y obra pedagógica de Lóris Malaguzzi. Barcelona: Octaedro, 2012. 
MAIA, Marta Nídia. Educação Infantil: com quantas datas se faz um currículo? 2013. 186 f. Dissertação (Mestrado em Educação) - Pontifícia Universidade Católica do Rio de Janeiro, Rio de Janeiro, RJ, 2013.

MINISTÉRIO DA EDUCAÇÃO (MEC). Conselho Nacional de Educação. Câmara de Educação Básica. Resolução CNE/CEB n. ${ }^{\circ}$ 5, de 17 de dezembro de 2009. Fixa as Diretrizes Curriculares Nacionais para a Educação Infantil. Diário Oficial da União, Brasília, DF, 18 dez. 2009. Seção 1, p. 18.

PAGANO, Andrea. Como o olhar dos adultos sustenta as aprendizagens das crianças. In: GARCIA, Joe; PAGANO, Andrea; JUNQUEIRA FILHO, Gabriel. Educação infantil em Reggio Emília: reflexões para compor um diálogo. Curitiba: UTP, 2017. p. 17-45.

PRADO, Alessandra Elisabeth Ferreira Gonçalves; AZEVEDO, Heloisa Helena Oliveira. Currículo para a educação infantil: argumentos acadêmicos e propostas de "educação" para crianças de 0 a 5 anos. In: ARCE, Alessandra; JACOMELI, Maria Regina Martins (Orgs.). Educação infantil versus educação escolar: entre a (des)escolarização e a precarização do trabalho pedagógico nas salas de aula. Campinas: Autores Associados, 2012. p. 33-52.

OLIVEIRA-FORMOSINHO, Julia. Pedagogia(s) da infância: reconstruindo uma práxis. In: OLIVEIRAFORMOSINHO, Júlia; KISHIMOTO, Tizuko Morchida; PINAZZA, Mônica Apezzato. Pedagogias da infância: dialogando com o passado construindo o futuro. Porto Alegre: Artmed, 2007. p. 13-36.

OLIVEIRA-FORMOSINHO, Julia; FORMOSINHO, João. Pedagogia-em-participação: em busca de uma práxis holística. In: OLIVEIRA-FORMOSINHO, Julia; PASCAL, Christine (Orgs.). Documentação pedagógica e avaliação na Educação Infantil: um caminho para transformação. Porto Alegre: Penso, 2019. p. 26-56.

OLIVEIRA, Zilma Ramos. Educação infantil: fundamentos e métodos. São Paulo: Cortez, 2011.

RINALDI, Carla. A pedagogia da escuta: a perspectiva da escuta em Reggio Emilia. In: EDWARDS, Carolyn; GANDINI, Lella; FORMAN, George. As cem linguagens da criança: a abordagem de Reggio Emília na educação da primeira infância. v. II. Porto Alegre: Penso, 2016. p. 235-247.

RINALDI, Carla. Documentação e avaliação: qual a relação? In: GIUDICI, Claudia; RINALDI, Carla. Tornando visível a aprendizagem: crianças que aprendem individualmente e em grupo. São Paulo: Phorte, 2014. p. 80-95.

RINALDI, Carla. O currículo emergente e o construtivismo social. In: EDWARDS, Carolyn; GANDINI, Lella; FORMAN, George. As cem linguagens da criança: a abordagem de Reggio Emília na educação da primeira infância. v. 01. Porto Alegre: Artes Médicas, 1999. p. 107-116.

ROCHA, Eloisa Acires Candal. A pedagogia e a educação infantil. Revista Brasileira de Educação, Rio de Janeiro, n. 22, p. 27- 34, jan./abr. 2001.

SACRISTÁN, José Gimeno. O que significa currículo? In: SACRISTÁN, José Gimeno (Org.). Saberes e incertezas sobre o currículo. Porto Alegre: Penso, 2015. p. 16-37.

SAVIANI, Dermeval. Pedagogia histórico-crítica: primeiras aproximações. 11. ed. Campinas: Autores Associados, 2012.

SILVA, Marcelo Oliveira; CARVALHO, Rodrigo Saballa. A entrevista como possibilidade dialógica na produção de dados em uma pesquisa sobre práticas pedagógicas de professores. In: SANTOS, Amanda Basílio et al. (Orgs.). Fontes, métodos e abordagens nas ciências humanas: paradigmas e perspectivas contemporâneas. Pelotas: BasiBooks, 2019.

VITTA, Fabiana Cristina Frigieri; CRUZ, Girlene Albuquerque; SCARLASSARA, Barbará Solana. A Base Nacional Comum Curricular e o berçário. Horizontes, v. 36, n. 1. p. 64-73, jan./jun. 2018.

\section{Correspondência}

Marcelo Oliveira da Silva: É Pós-doutorando em Educação pela UFRGS. Doutor em Educação pela PUCRS.

E-mail: moliveiras@gmail.com

Rodrigo Saballa de Carvalho: É Professor do Programa de Pós-Graduação em Educação da na Linha de Pesquisa: Estudos sobre Infâncias. Professor da área de Educação Infantil do Departamento de Estudos Especializados (DEE) da Faculdade de Educação da UFRGS.

E-mail: rsaballa@terra.com.br

Texto publicado em Currículo sem Fronteiras com autorização dos autores 